\title{
Clinical Images
}

\section{Retrieval of an Ingested Toothbrush in a 16-Year-Old Girl}

\author{
A.K. Saxena H. Ainoedhofer J.Schalamon \\ Department of Pediatric Surgery, Medical University of Graz, Graz, Austria
}

A 16-year-old girl presented to our emergency department with left-sided pain in the upper abdomen. The patient had no previous history of abdominal pain. Auscultation of the abdomen revealed normal bowel movements. According to her dietary habits, she was a vegan. The patient's attitude during the physical examinations was uncooperative and withdrawn. A plain abdominal X-ray was performed (fig. 1). When confronted with the image, the patient admitted to have swallowed a toothbrush of adult size. The patient presumed that she had unknowingly consumed meat, and in efforts to provoke vomiting with the toothbrush, it was accidentally swallowed. Under general anesthesia, the toothbrush was removed using an endoscope, with the head of the toothbrush grasped with a snare. There was no injury or complication during endoscopic retrieval (fig. 2). The postoperative course was uneventful.

Fig. 1. Abdominal film, showing the presence of a suspected foreign body in the left upper quadrant.

\begin{tabular}{ll}
\hline KARGER & ( ) 2007 S. Karger AG, Basel \\
Fax +41 61306 1234 $34-4886 / 07 / 0246-0477 \$ 23.50 / 0$ \\
$\begin{array}{l}\text { E-Mail karger@karger.ch } \\
\text { www.karger.com }\end{array}$ & $\begin{array}{l}\text { Accessible online at: } \\
\text { www.karger.com/dsu }\end{array}$
\end{tabular}

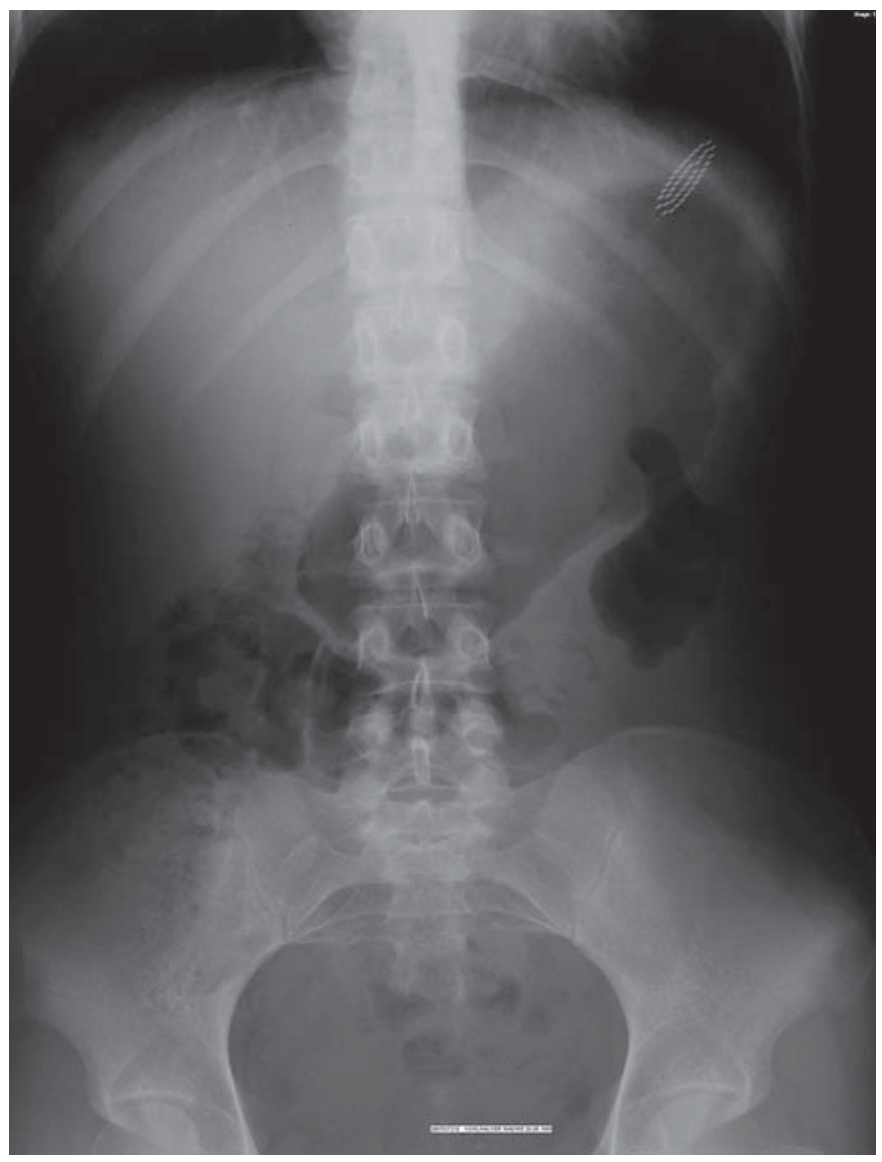

Amulya K. Saxena, MD

Department of Pediatric Surgery, Medical University of Graz

Auenbruggerplatz 34

AT-8036 Graz (Austria)

Tel. +43 316385 3762, Fax +43 316385 3775, E-Mail amulya.saxena@meduni-graz.at 
Fig. 2. Endoscopic view of the full-size adult toothbrush located in the stomach.

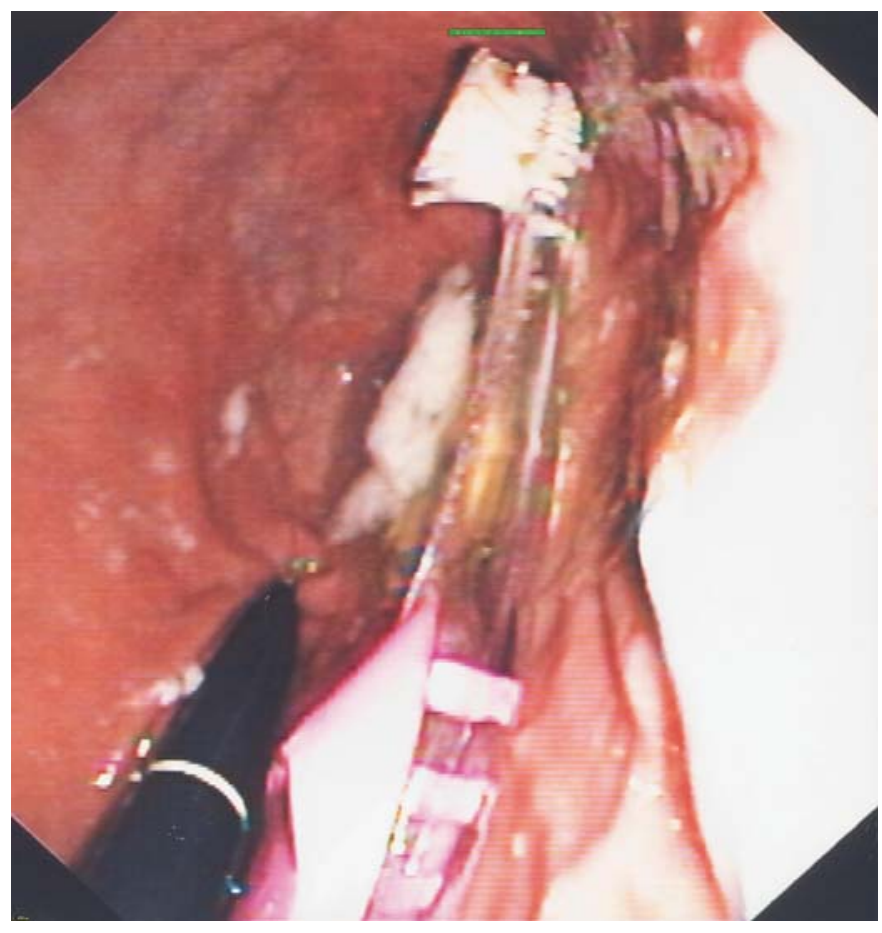

